\title{
RBEP
}

\section{Normatividade, políticas públicas educacionais e a questão racial no Brasil}

Sidney Reinaldo Silva

Mário Negrão

\section{Resumo}

Investiga a questão das cotas raciais nas políticas públicas de educação no Brasil, na perspectiva da normatividade. Num primeiro momento, são definidos a normatividade e seus âmbitos. Posteriormente é retomado um quadro teórico para se pensar o nexo entre democracia e direito como base para se analisar a relação entre políticas públicas e normatividade, especialmente no caso de políticas de ação afirmativa que envolvem o critério étnico. A partir da análise de uma situação concreta de debate normativo no Brasil, o texto aponta para a tendência atual da discussão em torno das políticas de cotas e indica os principais marcos normativos que se despontam em nosso País.

Palavras-chave: políticas públicas educacionais; cotas raciais; normatividade. 


\section{Abstract \\ Normativity, educational public policies and the racial question in Brazil}

The present article aimed at the racial quotas concerning educational policies in Brazil, in the normative perspective. First, there were defined the normativity and its scope. Later, the theoretical background was revised in order to analyze the relation between public policies and normativity through the link between democracy and law especially concerning the affirmative action policies with ethnical criteria. Through the analysis of a concrete situation of the normative debate in Brazil, the text points out the quotas policies discussion trends as well as the main normative frameworks in the country.

Keywords: educational public policies; racial quotas; normativity.

\section{Introdução}

Este texto analisa problemas de normatividade relacionados com políticas de ação afirmativa, especialmente as cotas raciais nas universidades públicas brasileiras. A partir de uma discussão em torno da "natureza" comunitarista da Constituição brasileira e sua correlação com os movimentos sociais, aponta a questão racial na Lei n 9.394, de 1996 - Lei de Diretrizes e Bases da Educação Nacional (LDB) -, alterada pelas Leis $n^{0}$ 10.639, de 2003, e no 11.645, de 2008, bem como nas Diretrizes Curriculares Nacionais para a Educação das Relações Étnico-Raciais e para o Ensino de História e Cultura Afro-Brasileira e Africana.

Trata-se de indicar dimensões normativas da questão da diversidade no âmbito da Educação no governo Lula como base para se discutir possíveis (in)congruências entre políticas públicas de cotas raciais nas universidades brasileiras e questões referentes à moral, à ética, à justiça e à política. A abordagem da temática se deu com uma reconstrução de posicionamentos e discursos normativos recentes em torno das políticas públicas de acesso à universidade pública no Brasil.

Mostra-se que o constitucionalismo comunitário, ao priorizar a dignidade humana dentro de uma esfera de solidariedade social, ultrapassa o formalismo jurídico, tal como defendem os liberais, aproximando-se, dessa forma, do ideário de políticas públicas voltadas para o reconhecimento. Contudo, a justificação comunitarista corre o risco de perder de vista a universalidade e a reciprocidade exigidas pela base moral de justificação. Assim, a justificação das políticas de ação afirmativa, especialmente as que envolvem cotas raciais, precisa ser definida no debate político próprio 
do âmbito da cidadania, onde questões éticas, morais e jurídicas podem ser confrontadas de forma democrática.

\section{Normatividade e a responsabilidade do judiciário na democracia}

A normatividade, neste texto, é vista como uma forma de se investigar a definição de princípios, valores e normas no âmbito público, numa tensão não só entre o justo e o bem, mas entre ética, moral, direito e política. Korsgaard (1996, p. 8) refere-se ao direito (right), no caso o justo, como algo moralmente necessário, ou seja, que tem que ser feito (that you ought to do it), e ao bem (good) como aquilo que pode ser objeto de recomendação, preferência, quer dizer, algo que vale a pena ser escolhido (worthy of your choice) e, mais profundamente, o que define nossas escolhas, o que vale a pena ser e fazer, perante o qual o Estado pode ou não ser neutro. Essa é uma linha de corte fundamental para se compreender a diferença entre a teoria da justiça liberal e a comunitarista: os liberais defendem a prioridade do justo sobre o bem, enquanto os comunitaristas afirmam que o bem, em sua acepção comum e/ou em seu sentido fragmentado dado pela diversidade de concepção de vida boa e valores, deve ter precedência sobre o justo, ou seja, sobre o arcabouço jurídico de uma coletividade.

Além dessa linha de corte da normatividade retomam-se também os âmbitos da normatividade tal como apresentados por Forst (2010). Este autor aponta as perspectivas ética, jurídica, política e moral referindo-se a âmbitos normativos que, embora estejam interligados, guardam também profunda autonomia uns em relação aos outros.

No âmbito ético, o da diversidade étnica, religiosa, valorativa, etc., está em jogo o que uma pessoa ou comunidade pode querer para si mesmo, pode entender como valioso e digno de ser promovido. Assim, um valor tem força quando é determinante da identidade "para alguém" como membro de uma comunidade ética, dando sentido para a "sua" vida. Alguém responde a questões éticas por meio da referência àquilo com que se identifica (Forst, 2010, p. 310): religião, tradição ou outras fontes e referências para o sentido da vida. Embora a etnicidade possa ser fonte de valores e de sentidos de vida ligados à especificidade de um grupo, injustiças ligadas a ela exigem um tratamento em outras esferas de normatividade ou âmbitos de justiça.

O contexto ou âmbito jurídico refere-se àquilo que uma comunidade de direito impõe a seus membros como necessário para a garantia da convivência comum, para que cada um possa definir sua "vida boa" e desenvolver-se livremente como ser ético.

Já no âmbito da política, os cidadãos atuam como definidores de normas comuns nos mais diversos espaços democráticos que uma coletividade garante como esfera de participação. As obrigações políticas "são autoimpostas", e suas normas devem ser justificadas como válidas universalmente para uma determinada comunidade política. "Os cidadãos 
são responsáveis pelo direito, enquanto que as pessoas do direito são responsáveis diante do direito." (Forst, 2010, p. 213. Grifos do autor).

A moral, por sua vez, constituiria um âmbito dado pelo reconhecimento de uma humanidade comum que exige que certos princípios e direitos sejam respeitados no sentido de garantir a dignidade das pessoas não como pertencendo a uma comunidade ética ou jurídica, mas cosmopolita. Segundo Forst (2010, p. 232), julgar moralmente "significa considerar, como ser humano, outros seres humanos como membros de uma comunidade abrangente de todos os seres humanos e ter diante de cada um, aqui e agora, uma atitude que pode ser justificada com razões"; trata-se de justificações com base na universalidade e na reciprocidade. Entende-se, no presente texto, que uma investigação normativa ou uma teoria da justiça possibilita definir e reunir os contextos de justificação: o ético, o jurídico, o político e o moral.

Partindo desse quadro de normatividade, poder-se-ia dizer que o problema das cotas raciais dificilmente ocorreria dentro de uma estrutura social unificada por uma visão global, na qual a "eticidade" se fundamentasse em valores tradicionais compartilhados por todos de maneira igual. Essa unidade ética, caso ainda fosse possível, constituiria um sistema de pensamento que serve para um referencial de ação legitimadora da ordem social existente, "estabelecendo-a não apenas como a desejável, mas como a única possível" (Nobre, 2008). Dessa forma, uma distribuição desigual de bens e direitos não seria um problema e sim o resultado de uma suposta ordem natural das coisas. Esse tipo de comunidade constituiu-se historicamente antes do advento da sociedade moderna.

Com a modernidade, diferentemente da forma de viver tradicional acima descrita, os membros de uma comunidade são obrigados a conviver dentro de uma pluralidade de concepções de mundo, muitas vezes conflitantes, onde as diversas concepções éticas impossibilitam a legitimação de uma ordem social através de uma tradição unificadora. Tem-se o desafio de encontrar uma maneira de estabelecer uma ordem social que não esteja ancorada numa unidade espiritual ou ética dada por uma tradição hegemônica.

Um ponto de partida para fundamentar essa nova ordem de convivência foi o de buscar uma base moral fundada no compartilhamento de direitos inalienáveis do homem, como aqueles estabelecidos durante a Revolução Francesa de 1789. Nessa concepção normativa, pode se pensar a sociedade derivando de um contrato social, na qual o consentimento forma um corpo político, criando "critérios e instituições que permitem aos indivíduos e grupos aceitar a ordem social que daí resulta" (Nobre, 2008 p. 18). Dito de outra maneira, a legitimidade social assentar-se-ia em normas estabelecidas pelos próprios membros da comunidade que fundamentam suas decisões jurídicas num código costurado pelo consentimento. O âmbito do político recebe uma primazia normativa. Num sentido ideal, o cidadão encontra sua liberdade no fato de que as leis que ele segue foram formuladas pelos membros da comunidade a que pertence e às quais ele próprio teria consentido. 
No entanto, o fato de que a moral e consequentemente a política e o direito não se encontram mais subordinadas a uma unidade ética tradicional, e sim ao próprio funcionamento dessa sociedade, ao seu sistema procedimental que a legitima, o direito deixa de ser natural e assume um aspecto positivo, tornando difícil uma concepção política unificante, sem valor moral, pois não se pode obrigar uma pessoa a desejar o bem através da lei. Nobre (2008) mostra que, ante a impotência de um novo consenso geral, o mercado passa a ser um princípio regulador visto como neutro e capaz de ganhar a adesão de todos, numa sociedade em que o foco normativo foi se deslocando do homem para a produção. Isso culminou com a autonomização dos diversos setores da sociedade, cada um seguindo a sua lógica própria, tendo como base normativa os critérios da produção e reprodução do capital.

Assim, a sociedade moderna pode encontrar condições para reproduzir materialmente devido ao deslocamento do foco da normatividade para a impessoalidade do mercado. Nessa lógica, o mundo e os atores sociais se desvestem de opiniões, visões do mundo e crenças e passam a ser meros objetos com vista à consecução de um fim determinado, que seria o manter a reprodução de espaços sociais e preferências de mercado. O tipo de ação social característico dessa lógica é, para Habermas, a ação instrumental voltada para o êxito pessoal.

Numa democracia, ao se questionar tais formas de legitimidade sistêmicas (Estado/contrato e mercado), entende-se que essa neutralização instrumental muitas vezes não é suficiente para eliminar os potenciais de conflito e dissenso decorrentes da sociedade moderna, exigindo-se outra forma de lidar com os dissensos. Essa outra maneira de lidar com as condições de instabilidade acima mencionada se faz através da discussão racional, livre de impedimentos, "nas quais as próprias regras da discussão têm que ser estabelecidas pelos participantes" (Nobre, 2008, p. 21). É o tipo de ação que Habermas chama de comunicativa, que tem como finalidade os entendimentos entre os membros da discussão permitindo que se encontrem ideais e valores (que os ingleses chamam de common ground) compartilhados por esse grupo que serviria como um referencial normativo suficiente para se resolverem as questões em pauta.

Esses dois tipos de ação correspondem também a domínios próprios que passam a exigir uma articulação (Nobre, 2008). Retomando as categorias habermasianas, tem-se que o domínio da vida social onde predomina a ação instrumental é denominado de "sistema", enquanto o domínio social onde predomina a ação comunicativa é chamado de "mundo da vida". Contudo, o mundo da vida é permeado pela dimensão ética, pela diversidade de valores e exigências baseados em idiossincrasias. Esses dois domínios já se encontravam nas sociedades tradicionais, mas ganharam novos conflitos e dissensos atuais quando na sociedade moderna foram desvinculados um do outro e suas lógicas específicas ganharam autonomia. Em consequência disso, foi necessário buscar meios para que a ação democrática transite entre os imperativos sistêmicos e as ações comunicativas no mundo da vida. Buscou-se dessa maneira uma nova 
espécie de articulação entre essas duas dimensões. É justamente essa a posição e função do direito, que tem qualificações para servir de entidade mediadora por pertencer simultaneamente a esses dois mundos.

Essa visão gera ao mesmo tempo dois problemas importantes: primeiramente, é necessário determinar a natureza do fluxo comunicativo em direção ao sistema administrativo, o que equivale a mostrar como se relacionam os domínios do poder administrativo e do poder comunicativo, criando condições para a circulação do poder; em segundo lugar, é preciso resolver o problema de como transformar poder comunicativo em poder administrativo. Segundo Nobre (2008, p. 25), uma metáfora utilizada para caracterizar os obstáculos que têm de ser suplantados pelo influxo comunicativo é de "eclusa": o fluxo comunicativo teria o poder de não somente atingir os patamares superiores do sistema como também poder refluir sem impedimentos para o mundo da vida, sem ameaçar a lógica instrumental que caracteriza essas ações.

Uma solução para o segundo problema aventada por Habermas (2010) seria transformar o poder comunicativo em poder administrativo. Como mencionado acima, o direito poderia exercer semelhante papel e função por ser uma instância que pertence ao sistema sem ser encapsulada por ele. Nobre (2008 p. 175) lembra a possibilidade de o judiciário e o direito constituírem um "quarto poder", como de certo modo acontece no Brasil com o Ministério Público e com o Supremo Tribunal Federal (STF).

\section{Constitucionalismo "Comunitário" contra o formalismo jurídico liberal}

O comunitarismo afirma a importância da participação, a mais ampla e legítima possível, nos fóruns democráticos, sobretudo locais. O surgimento de uma sociedade aberta de intérpretes da Constituição na educação brasileira teve seu início, segundo Cunha (1991, p. 92), com a ampliação do espectro de interesses da Sociedade Brasileira para o Progresso da Ciência (SBPC), a qual, com suas reuniões anuais, abrigou, a partir de 1970, os mais diversos tópicos de interesse geral, desde política salarial até a energia nuclear, entre outros, criando um fórum de debates entre acadêmicos, constituindo-se assim como um dos poucos espaços livres daquela época para a expressão das demandas políticas da sociedade brasileira.

Uma expansão desse espaço de debates ocorreu pouco tempo depois, com o cruzamento entre o movimento sindical dos professores, a difusão da crítica acadêmica da educação e a ampliação dos espaços de debates que se travaram depois da anistia, em 1979, aos opositores do governo militar.

Outro importante marco para a participação da sociedade na integração da realidade no processo de interpretação constitucional ocorreu quando a Associação Nacional de Pós-Graduação e Pesquisa em Educação (ANPEd), o Centro de Estudos Educação e Sociedade (Cedes) e a Associação Nacional dos Docentes do Ensino Superior (Andes) vieram 
a promover, a partir de 1980, as Conferências Brasileiras de Educação (CBE), versando a primeira sobre o tema "política educacional". Depois vieram as de 1982, sobre "educação: perspectiva na democratização da sociedade"; 1984, sobre "da crítica às propostas de ação"; 1986, sobre "A educação e a constituinte"; e de 1988, sobre "A LDB". Não se esquecendo da importância de todas essas conferências, "é possível afirmar que o produto de maior efeito sociopolítico de todas as conferências foi a Carta de Goiânia, da IV CBE de Goiânia, 1986" (Cunha, 1991), criando 21 dispositivos reclamados para a nova Constituição, entre os quais se destacavam: educação escolar como direito de todos e dever do Estado; educação gratuita e laica; e destinação dos recursos públicos exclusivamente para o ensino público, estabelecendo como competência da União legislar sobre assuntos educativos. Infelizmente, nem tudo do que foi pedido na Carta de Goiânia acabou se incluindo na Constituição de 1988, mas esta foi o início da ideia, no âmbito da educação, de uma sociedade aberta para os intérpretes da Constituição.

São três os motivos pelos quais se pode aventar que a Constituição de 1988 possui um caráter comunitário, ao assumir uma natureza não-interpretativista e zeladora do princípio da dignidade, tanto individual como coletiva, à diferença do interpretativismo, e preocupação em colocar todo cidadão no mesmo plano de igualdade tão característica da constitucionalidade anglo-saxã: primeiramente, a Comissão Provisória de Estudos Constitucionais de 1985, presidida por Afonso Arinos (por isso, também denominada Comissão Afonso Arinos), colocando como objetivo constitucional a dignidade dos brasileiros como atribuição do Estado, difere da concepção universalista, onde o Estado assume uma posição de maior neutralidade. Se pudermos aqui evocar o pensamento de Heller (1998), fica evidente que o Estado brasileiro pretende se moldar na concepção eticopolítica, ao invés da concepção sociopolítica. No Anteprojeto José Afonso, ${ }^{1}$ reza uma parte do artigo 40:

Incumbe aos poderes públicos promover as condições para que a igualdade e a liberdade sejam reais e efetivas, removendo os obstáculos de ordem econômica e social que impeçam o pleno desenvolvimento da pessoa humana e a participação de todos os trabalhadores na organização política, econômica, social e cultural do País. (Cittadino, 2009, p. 37).

Dessa maneira, a Constituição contém no seu corpo normativo um sistema de valores, realizados através do procedimento hermenêutico de captação de sentido do conteúdo das normas, que equivale a uma realização desses valores. O conceito do "bom" supera o conceito do "dever ser", adquirindo assim uma dimensão axiológica. Esse tipo de ordenamento constitucional assegura aos indivíduos uma esfera de liberdade ante o poder público, visto que o binômio verificação/falsificação é superado por validação/invalidação, pois cabe que uma norma poderá ser considerada como sendo justa ou injusta, com a possibilidade de poder ser revista ou substituída, em vez de ser obedecida ou não. Mais uma vez se pode notar
${ }^{1}$ N. do E. - José Afonso da Silva, redator do anteprojeto de Constituição elaborado pela Comissão Afonso Arinos. 
a influência de uma tendência não interpretativista dessa Constituição, colocando-a mais próxima do sistema de direito continental adotado na Espanha e em Portugal, onde o juiz toma como base a Lei escrita (procedimento hermenêutico), diferente da Common Law, que obedece à regra do precedente. Em resumo, perante um conflito entre direitos fundamentais, juízes e tribunais podem recorrer a "valores supremos" para solucionar o caso. "Outra inclusão à Constituição de 1988 que atesta sua característica "comunitária" é a possibilidade da participação direta de indivíduos ou coletividades na formação dos atos de governo" (Cittadino, 2009, p. 47). Essa possibilidade é viabilizada através de institutos populares de participação direta ou indireta pelo mandado de segurança coletivo, ação popular, denúncia de irregularidades, mandado de injunção e ainda pela ação de inconstitucionalidade por injunção, que permitem que o povo apresente projetos de lei ao Legislativo. Finalmente, o povo pode expressar sua vontade mudando atos de governo através do plebiscito.

Um segundo motivo para o comunitarismo refere-se ao fato de que a Constituição de 1988 assume "um amplo sistema de direitos fundamentais, acompanhado dos institutos processuais que visam controlar a omissão do poder público" (Cittadino, 2009, p. 37), sendo o mandado de injunção e a ação de inconstitucionalidade por omissão os institutos acolhidos pela Constituição Federal que melhor representam a "comunidade de intérpretes" para a concretização da Constituição. Dito de outra forma, o mandado de injunção toma por finalidade exigível e acionável os direitos humanos e suas liberdades que a Constituição não protege por falta de norma regulamentadora. O termo ação de inconstitucionalidade por omissão tem valor semelhante, porém não especificamente a questões de direitos humanos (Hauser, 1999). A referência à omissão do poder público oferece um maior grau de criatividade na interpretação da lei, pois, na ausência de uma norma clara, juízes podem decidir à luz de princípios, tanto de ordem constitucional quanto em comum acordo com normas internacionais de direito. O mesmo anteprojeto acima citado ensina que, "na falta de leis, decretos ou atos necessários à aplicação dessas normas, o juiz ou tribunal competente para o julgamento suprirá a lacuna, à luz dos princípios fundamentais da Constituição e das Declarações Internacionais de Direitos de que o País seja signatário, recorrendo de ofício, sem efeito suspensivo, para o Tribunal Constitucional" (Cittadino, 2009, p. 37).

$\mathrm{O}$ mandado de injunção encontra sua origem no termo writ of injunction da lei inglesa, eventualmente incorporada na lei americana, tendo sido usada nos Estados Unidos da América do Norte para coibir a segregação racial nas escolas, sendo a única ação constitucional que autoriza um juiz a romper com a tradicional aplicação rígida da lei (Cittadino, 2009, p. 51).

O terceiro elemento que confere características comunitaristas à Constituição de 1988 se mostra na capacidade da interpretação constitucional por valores graças ao poder político conferido ao STF. Originalmente concebida por Plínio de Arruda Sampaio como uma Corte Constitucional que integraria a "comunidade de intérpretes" servindo 
como intermediador entre indivíduos e coletividades na formação de atos de governo, foi ao STF que esse papel foi dado, graças à reação gerada por forças conservadoras que participaram na formação da Constituição de 1988. Cabe ao STF, "como órgão de caráter público, que atue no sentido de zelar para que o processo de elaboração legislativa ocorra sob as condições de uma política deliberativa" (Cittadino, 2009, p. 39). Mesmo assim foi decidido que a Corte Suprema deve recorrer à legitimização de aspirações sociais e não de seu bloqueio.

Deve-se recordar, contudo, que o comunitarismo refere-se à prioridade do bem sobre o justo, e isso se torna cada vez mais complicado numa sociedade em que o bem ético se fragmenta cada vez mais. Em seus comentários sobre a política do reconhecimento de Charles Taylor, Habermas (1994, p. 144) usa a metáfora da rede para falar da constituição do mundo da vida como âmbito preliminar do entendimento. Há, conforme o autor, uma

rede ascriptiva de culturas e tradições, de contextos de vida e de experiências intersubjetivamente partilhados. E esta rede também forma o horizonte dentro do qual os cidadãos da nação, querendo ou não, conduzem os discursos ético-políticos nos quais tentam chegar a um acordo sobre o seu próprio autoentendimento.

Contudo, para Habermas (1989, p. 131), numa era pós-convencional em que nenhuma cultura ou concepção ética consegue se impor como ideário para a totalidade dos cidadãos, a democracia precisa articular direito e ética, justiça e o bem viver,

as questões morais, que podem, em princípio, ser decididas racionalmente do ponto de vista da possibilidade de universalização dos interesses ou da justiça, são distinguidas agora das questões valorativas que se apresentam sob o mais geral dos aspectos como questões do bem viver (ou da auto-realização) e que só são acessíveis a um debate racional no interior de um horizonte não-problemático de uma forma de vida historicamente concreta ou de uma conduta de vida individual. [Grifos do autor].

Questões éticas, aquelas ligadas à vida boa, não podem ser avaliadas no interior do ponto de vista moral, no sentido de se definir politicamente se algo é bom para todos, pois, como foi acima indicado, o julgamento imparcial de semelhantes questões só pode ser feito segundo o autoentendimento e os projetos de vida de grupos específicos. Ao falar em estruturas de intersubjetividade intactas, de uma comunicação não distorcida, Habermas (1999, p. 191) propõe um consenso em torno de procedimento deliberativo legítimo. Segundo ele "enquanto as regras morais, ao formular aquilo que é do interesse de todos, exprimem uma vontade moral pura e simples, as regras jurídicas exprimem uma vontade particular dos membros de uma comunidade jurídica". A democracia constitui-se como espaço público onde se defrontam pretensões de validade da justiça que arrogam a universalidade e os valores que expressam as preferências e os bens que comunidades específicas ambicionam numa certa circunstância. 


\section{A perspectiva da Constituição Federal de 1988 e das políticas educacionais para as cotas raciais}

Poucas coisas despertam na atual sociedade brasileira sentimentos morais tão fortes como a questão das cotas raciais. Isso, de certo modo, leva a questionar o significado da Constituição ante as políticas públicas. Uma constituição é elaborada dentro de uma análise interpretativa da história que a precede, adquirindo assim um caráter vinculante e "supralegal" (Paixão, Carvalho Netto, 2010). Um amplo sistema de ações afirmativas que contempla cotas para negros é uma mostra clara do caráter aberto e inclusivo da nossa Constituição, quando estabelece no art. $5^{\circ}$, § $2^{\circ}$, que "os direitos e garantias expressos [na] Constituição não excluem outros decorrentes do regime e dos princípios por ela adotados, ou dos tratados internacionais em que a República Federativa do Brasil seja parte" (Brasil, 1988). Isso, de certo modo, repercute na legislação sobre a educação.

A LDB, Lei $n^{\circ}$ 9.394, de 20 de dezembro de 1996, promulgada no governo de Fernando Henrique Cardoso, faz menção, mediante alteração introduzida pela Lei $\mathrm{n}^{\circ}$ 10.639, de 9 de janeiro de 2003, quanto à necessidade de despertar uma consciência negra incorporada às políticas públicas educacionais. No entanto, o artigo 43, no capítulo IV, referente às finalidades da educação superior, permanece silencioso quanto a qualquer tentativa de se endereçar a questão de ações afirmativas para o ensino superior. O artigo 44, inciso II, no mesmo capítulo, deixa bem claro que a admissão aos cursos de graduação está aberta "a candidatos que tenham concluído o ensino médio ou equivalente e tenham sido classificados em processo seletivo". O capítulo V se dedica aos alunos com necessidades especiais, sem especificar quais são essas necessidades.

Fiel aos princípios liberais e da neutralidade do Estado, não houve nesse período, por meio desses instrumentos, uma clara tentativa de aplicar critérios interpretativos constitucionais com fundo histórico social ou afirmativo, deixando evidente que a orientação a ser seguida seria de natureza sociopolítica e não ético-social. Em 2003, durante o governo Lula, a Lei no 9.394 foi acrescida de dois artigos, mediante alteração introduzida pela referida Lei $n^{\circ} 10.639$ :

Art. $1^{\circ}$ A Lei $n^{\circ}$ 9.394, de 20 de dezembro de 1996, passa a vigorar acrescida dos seguintes arts. 26-A, 79-A e 79-B:

"Art. 26-A. Nos estabelecimentos de ensino fundamental e médio, oficiais e particulares, torna-se obrigatório o ensino sobre História e Cultura Afro-Brasileira.

$\S 1^{\circ}$ O conteúdo programático a que se refere o caput deste artigo incluirá o estudo da História da África e dos Africanos, a luta dos negros no Brasil, a cultura negra brasileira e o negro na formação da sociedade nacional, resgatando a contribuição do povo negro nas áreas social, econômica e políticas pertinentes à História do Brasil.

$\S 2^{\circ}$ Os conteúdos referentes à História e Cultura Afro-Brasileira serão ministrados no âmbito de todo o currículo escolar, em especial nas áreas de Educação Artística e de Literatura e História Brasileira. 
[...]

"Art. 79-B. O calendário escolar incluirá o dia 20 de novembro como 'Dia Nacional da Consciência Negra'."

Art. $2^{\circ}$ Esta Lei entra em vigor na data de sua publicação.

Brasília, 9 de janeiro de 2003; $182^{\circ}$ da Independência e $115^{\circ}$ da República. (Brasil, 2003).

A Resolução $\mathrm{n}^{\circ} 1$ do CNE, de 17 de junho de 2004, com fundamentação no Parecer CNE/CP 03/2004, estabelece, em seu art. $2^{\circ}$, que

As Diretrizes Curriculares Nacionais para a Educação das Relações Étnico-Raciais e para o Ensino de História e Cultura Afro-Brasileira e Africanas constituem-se de orientações, princípios e fundamentos para o planejamento, execução e avaliação da Educação, e tem por meta promover a educação de cidadãos atuantes e conscientes no seio da sociedade multicultural e pluriétnica do Brasil, buscando relações étnico-sociais positivas, rumo à construção de nação democrática. (Brasil. CNE, 2004).

A já citada Lei no 10.639, de 2003, contêm referências à proteção da cultura negra. Dignas de nota são as matérias contidas no art. 79-A, que se refere ao ensino de cultura negra no sistema de ensino geral (vetado), e o artigo 79-B, que reserva o dia 20 de novembro como "Dia Nacional da Consciência Negra", ambas trazidas de volta em 2008, no segundo governo Lula, através da Lei no 11.645, de 10 de março de 2008, que dá nova redação ao art. 26-A e seus parágrafos:

Art. 26-A Nos estabelecimentos de ensino fundamental e de ensino médio, públicos e privados, torna-se obrigatório o estudo da história e cultura afro-brasileira e indígena.

$\S 1^{\circ}$ O conteúdo programático a que se refere este artigo incluirá diversos aspectos da história e da cultura que caracterizam a formação da população brasileira, a partir desses dois grupos étnicos, tais como o estudo da história da África e dos africanos, a luta dos negros e dos povos indígenas no Brasil, a cultura negra e indígena brasileira e o negro e o índio na formação da sociedade nacional, resgatando as suas contribuições nas áreas social, econômica e política, pertinentes à história do Brasil.

$\S 2^{\circ}$ Os conteúdos referentes à história e cultura afro-brasileira e dos povos indígenas brasileiros serão ministrados no âmbito de todo o currículo escolar, em especial nas áreas de educação artística e de literatura e história brasileiras. (Brasil, 2008).

A referida Lei no 11.645/2008, que se estende aos estabelecimentos de ensino fundamental e médio de natureza oficial ou particular, torna obrigatório o ensino de cultura negra, no âmbito da História da África e dos Africanos, abrangendo a luta dos negros no Brasil, a cultura negra brasileira e o negro na formação da sociedade nacional, no sentido de resgatar "as suas contribuições nas áreas social, econômica e política, pertinentes à história do Brasil". 
Apesar do entusiasmo inicial, alguns problemas surgiram quanto à aplicação da lei. Vigorito (2008) relata dificuldades na implantação das determinações contidas na Lei n ${ }^{\circ}$ 10.639/03 em escolas públicas de Pelotas, no Rio Grande do Sul. Seu estudo foi executado através de entrevistas com duas diretoras que declararam suas dificuldades em implementar a lei devido à falta de recursos, tanto de material didático quanto de pessoal - outros estudos apontam o mesmo problema. Constatou-se que há falta não só de materiais didáticos, mas sobretudo de professores preparados para o ensino de história e cultura afro-brasileiras nas escolas de todo o País. É reconhecido o avanço trazido pelo Plano Nacional de Implementação das Diretrizes Curriculares Nacionais para Educação das Relações ÉtnicoRaciais, contudo ainda é necessário superar as dificuldades de sua implementação nas escolas, e a principal delas é a questão da formação dos professores. O tema tem sido pouco abordado mesmo nas faculdades de história - o que então pensar de outras licenciaturas? Para Silva (2008), este é um problema delicado que precisa ser enfrentado.

Segundo Fernandes (2005), os livros didáticos estão permeados por uma "concepção positivista" da historiografia brasileira, conferindo uma orientação teórica metodológica através de um conteúdo programático primado por uma visão monocultural e eurocêntrica do passado brasileiro, podendo isso se configurar como um exemplo claro de falta de reconhecimento associada ao reconhecimento errôneo, colocando nas próprias escolas a incumbência de difundir conceitos capazes de serem caracterizados como falta do respeito devido. Para Walzer (1994), os opostos do reconhecimento podem ser reconhecimentos desfavoráveis (desonra) ou ausência de reconhecimento (indiferença). Honneth (2009) ressalta o perigo de tensões sociais no campo moral e não apenas de interesses ou da redistribuição, como defendido por Rawls (2008).

Ao examinar essas leis em conjunto, que provêm de contextos históricos e governos diferentes, fica marcante que ambas seguem uma linha de raciocínio direcionada a favorecer grupos étnicos (negros, necessidades especiais e índios), sem colocar como ênfase o debate entre direitos de indivíduos e de coletividades, bem como na forma como argumentos são levantados, contra ou a favor, e em que sentido eles podem ser analisados criticamente em termos normativos.

\section{Cotas raciais em julgamento: entre a moral, o jurídico, o político e a ética}

Para explicitar as relações entre políticas públicas de cotas raciais, Constituição brasileira, valores éticos e princípios morais, analisa-se agora uma situação específica, em que o Partido Democrata (DEM) arguiu a Universidade de Brasília (UnB) numa medida cautelar de descumprimento de preceito fundamental de tratamento igual.

Em 2009, o STF se viu perante a questão da validade ou não da aplicação de cotas raciais no exame vestibular de 2009 para admissão 
a cursos universitários na UnB, quando o DEM ajuizou a arguição de descumprimento de preceito fundamental APDF/186, visando declarar inconstitucionais os atos de poder público que levaram à criação do sistema de cotas raciais na UnB, alegando-se ofensa aos seguintes artigos da Constituição de 1988:

$1^{\circ}$, caput e inciso III [dignidade da pessoa humana];

$3^{\circ}$, inciso IV [promover o bem de todos, sem preconceitos de origem, raça, sexo, cor, idade e quaisquer outras formas de discriminação];

$4^{\circ}$, inciso VIII [repúdio ao terrorismo e ao racismo];

5', incisos: I [homens e mulheres são iguais em direitos e obrigações]; II [ninguém será obrigado a fazer ou deixar de fazer alguma coisa senão em virtude da Lei]; XXXIII [todos têm direito a receber dos órgãos públicos informações de seu interesse particular, ou de interesse coletivo ou geral, que serão prestados no prazo da lei, sob pena de responsabilidade, ressalvadas aquelas cujo sigilo seja imprescindível à segurança da sociedade e do Estado]; XLII [a pratica do racismo constitui crime inafiançável, sujeito à pena de reclusão]; LIV [ninguém será privado da liberdade ou de seus bens sem o devido processo legal];

37, caput [A administração pública direta e indireta de qualquer dos poderes da união, dos estados do distrito federal e dos municípios obedecerá aos princípios de legalidade, impessoalidade, moralidade, publicidade e eficiência];

205, caput [A educação, direito de todos e dever do Estado e da família, será promovida a incentivada com a colaboração da sociedade, visando ao pleno desenvolvimento da pessoa, seu preparo para o exercício da cidadania e sua qualificação para o trabalho];

207, caput [As universidades gozam de autonomia didático-científica administrativa e de gestão financeira e patrimonial, e obedecerão ao princípio de indissociabilidade entre ensino, pesquisa e extensão];

208, inciso V [acesso aos níveis mais elevados do ensino, da pesquisa e da criação artística, segundo a capacidade de cada um]. (Brasil, STF, 2009).

Defendeu o referido partido político, com isso, que o acesso aos direitos fundamentais no Brasil não é negado aos negros, mas aos pobres, e que o problema econômico está atrelado à questão racial. Alegou-se que o sistema de cotas da UnB pode agravar o preconceito racial, uma vez que institui a consciência estatal da raça, promovendo ofensa arbitrária ao princípio da igualdade e gerando discriminação reversa em relação aos brancos pobres, além de favorecer a classe média negra (Brasil, STF, 2009).

O posicionamento do ministro Gilmar Mendes, do STF, dentro do papel atribuído à Magna Corte como guardiã da Constituição, zelando por seu cumprimento principalmente à base de princípios, ressalta a dificuldade em determinar a legitimidade constitucional dos programas de ação afirmativa. Referindo-se a Alexy (2001) e à exigência constitucional de reconhecimento e proteção igual das diferenças, Mendes afirma que, de certo modo, impõe-se um tratamento desigual por parte da lei, o que esse autor chama de paradoxo da igualdade, onde uma igualdade de direito tem por consequência uma desigualdade de fato. O ministro 
tenta superar esse impasse evocando a fraternidade, um valor oriundo do fim do século $8^{\circ}$ :

Não posso deixar de levar em conta, no contexto dessa temática, as assertivas do mestre e amigo professor Peter Häberle, o qual muito bem constatou que, na dogmática constitucional, muito já se tratou e já se falou sobre liberdade e igualdade, mas pouca coisa se encontra sobre o terceiro valor fundamental da Revolução Francesa de 1789: a fraternidade. (Brasil, STF, 2009).

Dessa maneira, o tema das cotas raciais deixa de repousar na clássica concepção liberal de igualdade como um valor formal. Obedecendo ao espírito fundamental de natureza comunitária da Magna Carta de 1988, assim como de seus aperfeiçoamentos posteriores, foi reconhecido que, ao se justapor igualdade e fraternidade, as diferenças e particularidades humanas encontram uma possibilidade de harmonização normativa. A tolerância enquanto formatadora da igualdade impõe igual consideração à pluralidade de particularidades e diversidades tão características da espécie humana; consequentemente, no Estado democrático, a conjugação dos valores da igualdade e da fraternidade expressa uma normatividade constitucional no sentido de reconhecimento e proteção de minorias. Por esses motivos, o STF indeferiu a medida cautelar do DEM.

Estes fatos talvez apontem para uma área de contradição na sociedade brasileira, especialmente no que se refere a que corrente de distribuição de bens se deve seguir, guardando em mente que, ao tomar-se a direção universalista ou comunitária, também se define qual conceito de liberdade, igualdade e tipo de reconhecimento vai ser adotado. O pensamento jurídico brasileiro, representado por certos autores acadêmicos e por aqueles vinculados ao direito privado, é marcadamente positivista, comprometido com um liberalismo e privativismo representando uma "espécie de fratura" no seio das aspirações constituintes de 1988 (Cittadino, 2009, p. 14). Essa corrente liberal e privativista, da qual o DEM é caudatário, coloca-se em contraste com pensadores como José Afonso da Silva, Carlos Roberto Siqueira Castro e Paulo Bonavides, que apresentam argumentos elucidativos sobre o constitucionalismo comunitário brasileiro. José Afonso da Silva explica:

O constituinte rejeitou a chamada constituição sintética, que é a constituição negativa, porque construtora apenas de liberdade-negativa ou liberdade-impedimento, oposta ao modelo de constituição que às vezes se chama de constituição-garantia (ou constituição-quadro). A função garantia não só foi preservada como até ampliada na nova Constituição, não como mera garantia do existente ou como simples garantia das liberdades negativas ou liberdades-limites. Assumiu o novo texto a característica de constituição-dirigente, enquanto define fins e programa de ação futura (Silva apud Cittadino, 2009, p. 15).

É justamente esse conceito de uma constituição ativa e participativa que entra em choque com aquelas correntes de pensamento mais preocupadas com a preservação dos direitos individuais através de um Estado 
neutro para questões sociais que opera seu sistema jurídico excluindo interpretações valorativas, baseando-se mais num princípio de exclusão de diferenças. O constitucionalismo comunitário prioriza a dignidade humana dentro de uma esfera de solidariedade social que ultrapassa o formalismo presente na primazia do justo sobre o bem dos liberais. Contudo, a forma como Gilmar Mendes argumentou contra o DEM apelou para princípios morais universais que extrapolam ao mero horizonte comunitário, mostrando uma congruência da Carta Magna brasileira com as exigências da comunidade humana mais abrangente.

\section{Considerações finais}

Segundo Taylor (2000, p. 246), a identidade de alguém é definida no diálogo com os outros. As políticas públicas (re)constituem esse diálogo; contudo, isso pode se dar de maneira distorcida, o que afeta a imagem que certos grupos e classes internalizam de si mesmos. Numa sociedade democrática, isso precisa ser corrigido, caso contrário ela se torna cada vez mais doentia, injusta, o que decorreria de sua própria cegueira em relação às diferenças e à negação do reconhecimento e da distribuição de bens básicos a uma parte das pessoas que ela pretende constituir como cidadãs. Taylor (2000) chama a atenção para os riscos de uma forma de discriminação reversa como medida temporária visando equilibrar temporalmente os pratos da balança, de modo a permitir que as antigas regras cegas às diferenças "voltassem a vigorar"; nesse sentido, propõe "medidas cuja meta não é nos devolver a um eventual espaço social 'cego às diferenças', mas, pelo contrário, manter e cultivar o distintivo não só agora, mas sempre" (Taylor, 2000. p. 252). Para o autor, a diversidade aparece com um bem a ser promovido pelo Estado. Os liberais do DEM, de certo modo, também entendem a igualdade de tratamento como um valor ou bem a ser mantido pelo Estado. Nesse contexto, quando se trata de discutir a questão das cotas "raciais" para o acesso de negros a universidades públicas, a política desliza entre formas de justificação carentes de uma base moral capaz de articular igualdade de tratamento e reconhecimento constante da diferença. Assim pode-se compreender a dificuldade de se admitir politicamente as cotas para negros numa lei tão decisiva para a consolidação do respeito à diferença como é o caso do Estatuto da Igualdade Racial. A questão é: Até que ponto se pode interpretar as exigências de Taylor - de "medidas cuja meta não é nos devolver a um eventual espaço social 'cego às diferenças', mas, pelo contrário, manter e cultivar o distintivo não só agora, mas sempre" - como uma exigência moral, e não meramente ética, a ser incorporada politicamente em nosso sistema jurídico?

Apesar de a maioria das políticas públicas terem um caráter predominantemente inclusivo para grupos étnicos (Moehlecke, 2009), principalmente em relação à suposta raça negra, não é clara sua articulação, no âmbito da justificação normativa, com os princípios constitucionais, 
com as normas fundamentais que partilhamos como brasileiros, com as diversas concepções e valores ligados à etnia que fragmentam nosso horizonte ético e com as exigências morais ligadas aos acordos firmados internacionalmente sobre direitos humanos. Isto é preocupante, no sentido de que teorias mais amplas de normatividade exigem um equilíbrio entre seus princípios constituintes - a moral, o direito, a política e a ética -, sem o que as políticas públicas não "harmonizariam" esses vários contextos de justificação.

Assim, é preciso levar em conta as exigências normativas mais radicais (Fraser, 2003) não apenas de reconhecimento da diferença, mas também de redistribuição e participação democrática na própria formulação e implementação de tais políticas, especialmente no caso das cotas, quando se torna necessário discutir qual modelo de política afirmativa seria mais desejável do ponto de vista moral, ético e político, o que exige a promoção de um genuíno debate democrático no âmbito nacional, do qual o debate promovido pela demanda do DEM foi uma boa mostra.

Contudo, é preciso lembrar a importância dos fóruns com caráter ético de discussão de questão racial nas políticas públicas, especialmente daqueles vinculados a movimentos sociais com bandeiras específicas. No campo da educação, a Conferência Nacional de Educação (Conae) tornou-se um dos marcos de normatividade para as políticas públicas, sobretudo devido à riqueza do último eixo de seu Relatório Final, que faz indicações para Justiça social, educação e trabalho: inclusão, diversidade e igualdade. Suas pretensões abarcam um amplo leque de questões normativas, pois ela exige a garantia de uma educação pautada na justiça social; consideração do mundo do trabalho para além da teoria do capital humano; reconhecimento e diálogo com a diversidade; ampliação da noção de inclusão; e igualdade social. Isso deve ser feito como um enfrentamento do desafio de superar uma sociedade marcada por profundas desigualdades sociais, de classe, de gênero, étnico-raciais, geracionais e de pessoa com deficiência. A Conae pode ser vista como uma forma bem sucedida de articulação das diversas formas de normatividade, tal como foram definidas neste texto. A questão é a forma de como ela poderá democraticamente ser retomada para justificar políticas de cotas raciais de outras formas de ação afirmativa no campo educacional sem que sua força transformadora seja esmaecida.

\section{Referências bibliográficas}

ALEXY, Robert. Teoría de los derechos fundamentales. Madrid: Centro de Estudios Políticos y Constitucionales, 2001.

BRASIL. Lei no 9.394, de 20 de dezembro de 1996. Estabelece as diretrizes e bases da educação nacional. Disponível em: < http://portal. mec.gov.br/seed/arquivos/pdf/tvescola/leis/lein9394.pdf $>$. 
BRASIL. Lei $n^{\circ}$ 10.639, de 9 de janeiro de 2003. Altera a Lei no 9.394, de 20 de dezembro de 1996, que estabelece as diretrizes e bases da educação nacional, para incluir no currículo oficial da rede de ensino a obrigatoriedade da temática "História e Cultura Afro-Brasileira". Disponível em: <http://www.educacao.salvador.ba.gov.br/site/ documentos/lei-10639-2003.pdf $>$.

Lei $n^{\circ} 11.645$, de 10 de março de 2008. Altera a Lei $n^{\circ}$ 9.394, de 20 de dezembro de 1996, modificada pela Lei $\mathrm{n}^{\circ} 10.639$, de 9 de janeiro de 2003, que estabelece as diretrizes e bases da educação nacional, para incluir no currículo oficial da rede de ensino a obrigatoriedade da temática "História e Cultura Afro-Brasileira e Indígena". Disponível em: < http://www.planalto.gov.br/ccivil_03/_ ato2007-2010/2008/lei/l11645.htm>. . Constituição da República Federativa do Brasil de 1988.

Disponível em: <http://www.planalto.gov.br/ccivil_03/constituicao/ constitui\%C3\%A7ao.htm>.

BRASIL. Conselho Nacional de Educação (CNE). Conselho Pleno. Resolução no 1, de 17 de junho de 2004. Diário Oficial da União, Brasília, 22 de junho de 2004, Seção 1, p. 11.

Superior Tribunal Federal (STF). Medida cautelar em arguição de descumprimento de preceito fundamental 186-2. Distrito Federal, 2009. Disponível em: < http://www.stf.jus.br/arquivo/cms/ noticiaNoticiaStfArquivo/anexo/ADPF186.pdf $>$.

CONFERÊNCIA NACIONAL DE EDUCAÇÃO (Conae). Documento final, 2010. Brasília: MEC, 2010. Disponível em: <http://conae.mec.gov.br/ images/stories/pdf/pdf/documetos/documento_final_sl.pdf $>$.

CITTADINO, Gisele. Pluralismo, direito e justiça distributiva: elementos da filosofia constitucional contemporânea. 2. ed. Rio de Janeiro: Lumen Juris, 2009.

CUNHA, Luíz Antônio. Educação, Estado e democracia no Brasil. São Paulo: Cortez, 1991.

FERNANDES, José Ricardo Oriá. Ensino de História e diversidade cultural: desafios e probabilidades. 2005. Disponível em: <http://www. scielo.br/pdf/ccedes/v25n67/a09v2567.pdf>.

FRASER, N. Social justice in age of identity: redistribution, recognition, and participation. In: FRASER, N.; HONNETH, A. Redistribution or recognition? A political-philosophical exchange. London: Verso, 2003. 
FORST, Rainer. Contextos da justiça. São Paulo: Boitempo, 2010.

HÄBERLE, Peter. Hermenêutica constitucional. Porto Alegre: Sérgio Antônio Fabris, 1997.

HABERMAS, Jürgen. Direito e democracia entre facticidade e validade. Rio de Janeiro: Tempo Brasileiro, 2010.

1999.

. Comentários à ética do discurso. Lisboa: Instituto Piaget,

. Lutas pelo reconhecimento no Estado Constitucional

Democrático. In: TAYLOR, C. (Org.) Multiculturalismo: examinando a política do reconhecimento. Lisboa: Instituto Piaget, 1994.

Notas programáticas para a fundamentação de uma Ética do Discurso. In: HABERMAS, Jürgen. Consciência moral e agir comunicativo. Rio de Janeiro: Tempo Brasileiro, 1989. p. 61-141.

HAUSER, Denise. Mandado de injunção e ação de inconstitucionalidade por omissão. Jus Navigandi, Teresina, v. 4, n. 36, nov. 1999. Disponível em: <http://jus.com.br/revista/texto/127>.

HELLER, Agnes. Além da justiça. Rio de Janeiro: Civilização Brasileira, 1998.

HONNETH, Axel. Luta por reconhecimento: a gramática moral dos conflitos sociais. São Paulo: Ed. 34, 2009.

KORSGAARD, Christine. The sources of normativity. Cambridge: Cambridge University Press, 1996.

MOEHLECKE, Sabrina. As políticas de diversidade na educação no governo Lula. Cadernos de Pesquisa, São Paulo, v. 39, n. 137, p. 461-487, maio/ago. 2009.

NOBRE, Marcos. Direito e democracia: um guia de leitura de Habermas. São Paulo: Malheiros, 2008.

PAIXÃO, Cristiano; CARVALHO NETTO, Menelick. A política de ações afirmativas da UnB e a Constituição. Disponível em: < http://vsites. unb.br/fd/ced/index.php?option $=$ comcontent\&task = view\&id = 23\&Item $\mathrm{id}=1>$. Acesso em: 20 jul. 2010.

RAWLS, John. Uma teoria da justiça. 3. ed. São Paulo: Martins Fontes, 2008 . 
SILVA, Geovan João Alves da. Fórum para implementação da Lei 10.693/03. 2008. Disponível em: <http://www.ciranda.net/brasil/ ciranda-afro/article/forum-para-implementacao-da-lei-10> .

SILVÉRIO, Valter Roberto. Ação afirmativa e o combate ao racismo institucional no Brasil. Cadernos de Pesquisa. São Paulo, n. 117, p. 219246, nov. 2002.

TAYLOR, Charles et al. Multiculturalismo: examinando a política de reconhecimento. Lisboa: Instituto Piaget, 1994.

. Argumentos filosóficos. São Paulo: Loyola, 2000.

WALZER, Michael. Comentário. In: TAYLOR, Charles et al.

Multiculturalismo: examinando a política de reconhecimento. Lisboa:

Instituto Piaget, 1994.

VIGORITO, Raquel Garcia. A Lei no 10.639/03 nas escolas públicas na cidade de Pelotas/RS. Disponível em: < http://www.ufpel.edu.br/ cic/2008/cd/pages/pdf/CH/CH_01428.pdf>. Acesso em: 23 mar. 2011.

Sidney Reinaldo Silva, doutor em Filosofia pela Universidade Estadual de Campinas (Unicamp), é professor do Programa de Pós-Graduação em Educação da Universidade Tuiuti do Paraná (UTP).

sidney.silva@utp.br

Mário Negrão, doutorando em Educação pela Universidade Tuiuti do Paraná (UTP), é clínico neurologista e professor aposentado da Universidade Federal do Paraná (UFPR).

marneg@onda.com.br

Recebido em 19 de abril de 2011.

Aprovado em 18 de abril de 2012. 